\title{
Assessment of the masonry strength of the fortress in Terezin
}

\author{
M. Holicky, M. Sykora \& V. Vacek \\ Klokner Institute, Czech Technical University in Prague, Czech Republic
}

\begin{abstract}
Historic defensive structures are made of various types of masonry with significantly different material properties, suffering from different degrees of degradation. As a rule the information on mechanical properties of masonry components has to be obtained by testing. Estimation of masonry strength using measurements affected by various types of uncertainties appears to be a key issue of the reliability assessment. The probabilistic model of masonry strength is developed considering uncertainties in basic variables and testing procedures. Its application is illustrated by the assessment of masonry strength of the historic fortress in Terezin (Czech Republic). It is shown that the characteristics of masonry strength can be well estimated using fundamental statistical methods. The design strength obtained by the probabilistic approach may be considerably greater than the value obtained deterministically. The statistical uncertainty due to lack of data may significantly affect the predicted design value.
\end{abstract}

Keywords: historic masonry, compressive strength, probabilistic methods, fortress.

\section{Introduction}

Historic defensive structures are made of various types of masonry made from stones, fired or sundried clay bricks joined together by lime or cement mortars. Masonry is commonly exposed to environmental influences including volume changes due to moisture and temperature changes, freeze-thaw attack or salt crystallisation. These influences result in large variability of material properties that are to be estimated using tests. The evaluation of data concerning masonry strength is then a key task in the reliability assessments of heritage buildings. 
Previous studies revealed that deterministic verifications of existing structures tend to be conservative. Such approaches may be used for the design of new structures where required reliability may be achieved at a relatively low cost. In the case of historic structures, however, it may lead to expensive repairs and loss of heritage values. Probabilistic analysis is then desirable for the assessment of historical masonry [1-4] as it facilitates a rational consideration of:

- Randomness of material characteristics of masonry units and mortar;

- Statistical uncertainties due to a limited number of tests;

- Inaccuracies of testing (often non- or minor-destructive) methods;

- Simplifications adopted in the model for masonry strength (model uncertainty).

The probabilistic model of masonry strength is developed taking into account uncertainties in basic variables, testing procedures and in the theoretical model accepted for masonry strength. The estimation of compressive masonry strength in the direction perpendicular to bed joints is based on the model in EN 1996-1-1:2005 for design of masonry structures and by the Joint Committee on Structural Safety Probabilistic Model Code (JCSS PMC) [5].

\section{Models for compressive masonry strength}

\subsection{Deterministic model}

In accordance with EN 1996-1-1:2005 the characteristic compressive strength $f_{\mathrm{k}}$ of non-reinforced masonry made with general purpose mortar is obtained as follows:

$$
f_{\mathrm{k}}=K_{\mathrm{nom}} f_{\mathrm{b}}^{\alpha} f_{\mathrm{m}}^{\beta}
$$

where $K_{\text {nom }}=$ nominal value of the coefficient for the calculation of compressive strength of masonry; $f_{\mathrm{b}}=$ standardised strength of masonry units (mean value); $f_{\mathrm{m}}$ the strength of mortar (mean value); and $\alpha$ and $\beta=$ constants. As the historic masonry is commonly deteriorated, different constants $\alpha$ and $\beta$ may be accepted or relationships other than eqn. (1) might be considered [3].

The design value of masonry strength $f_{\mathrm{d}}$ is derived from the characteristic value by introducing the partial factor $\gamma_{M}$ (including uncertainties about geometry and modelling):

$$
f_{\mathrm{d}}=f_{\mathrm{k}} / \gamma_{\mathrm{M}}
$$

Considering $\alpha=0.65$ and $\beta=0.25$ for non-reinforced existing masonry with general purpose mortar, the Czech National Annex to ISO 13822:2010 suggests the partial factor $\gamma_{\mathrm{M}}$ as a product of the following four partial factors:

- $\gamma_{\mathrm{m} 0}$ - the basic value of the partial factor;

$-0.85 \leq \gamma_{\mathrm{m} 1} \leq 1.2$ - the coefficient considering the effect of the regularity of the masonry bond and the filling of joints with mortar; the lower limit of the interval applies to quite a regular bond and perfect filling of joints with mortar; 
- $1.0 \leq \gamma_{\mathrm{m} 2} \leq 1.25$ - the coefficient considering the effect of increased moisture, for masonry moisture in the interval from $4 \%$ to $20 \%$ the coefficient is obtained by interpolation;

- $1.0 \leq \gamma_{\mathrm{m} 3} \leq 1.4$ - the coefficient considering the effect of vertical and inclined cracks in masonry.

\subsection{Probabilistic model}

The deterministic formula (1) needs not always describe the actual masonry strength with adequate accuracy. To enhance estimates of $f_{\mathrm{k}}$ and $f_{\mathrm{d}}$, a simplified probabilistic model of masonry strength $f$ is proposed here (considering Section 3.2 of JCSS PMC [5]):

$$
f=K\left(\theta_{f \mathrm{~b}} f_{\mathrm{b}}\right)^{\alpha}\left(\theta_{f \mathrm{~m}} f_{\mathrm{m}}\right)^{\beta}
$$

where $\theta=$ uncertainty in estimation of the mean strength by a test method (possibly using appropriate conversion factors). Uncertainty in the conversion factor should be included in the auxiliary variable $\theta$. Since estimates of $f_{\mathrm{b}}$ and $f_{\mathrm{m}}$ are affected by the statistical uncertainty due to a limited sample size $n$, all the variables in eqn. (3) (apart from $\alpha$ and $\beta$ ) are random. Eqn. (3) can also account for the slenderness of a masonry member [5].

The coefficient $K$ is commonly described by a lognormal distribution with the origin at zero (hereinafter simply "lognormal distribution"). Lognormal distribution is also appropriate for the uncertainties $\theta$ [5]. The mean values $f_{\mathrm{b}}$ and $f_{\mathrm{m}}$ are described by the lognormal distribution with mean $\mu$ and standard deviation $\sigma[4]$ :

$$
\begin{aligned}
\mu=m ; \quad \sigma & =s \sqrt{ }\left[(n-1) /\left(n^{2}-3 n\right)\right] \\
\text { with } m=\sum_{i} f_{i} \text { and } s & =\sqrt{ }\left[\sum_{i}\left(f_{i}-m\right)^{2} /(n-1)\right] ; i=1 . . n
\end{aligned}
$$

where $m=$ unbiased estimate of the mean $\mu ; s=$ best estimate of the population standard deviation; and $f_{i}$ is a test result.

When all the basic variables in (3) are lognormal, then the resultant masonry strength has also a lognormal distribution. The logarithm $\ln f$ has a normal distribution with the characteristics:

$$
\begin{gathered}
\mu_{\ln f}=\mu_{\ln K}+\alpha\left(\mu_{\ln \theta_{\mathrm{b}}}+\mu_{\ln f \mathrm{~b}}\right)+\beta\left(\mu_{\ln \theta_{\mathrm{m}}}+\mu_{\ln f_{\mathrm{m}}}\right) \\
\sigma_{\ln f}=\sqrt{ }\left[\sigma_{\ln K^{2}}+\alpha^{2}\left(\sigma_{\ln \theta_{\mathrm{b}}}{ }^{2}+\sigma_{\ln f_{\mathrm{b}}}{ }^{2}\right)+\beta^{2}\left(\sigma_{\ln \theta_{\mathrm{m}}}{ }^{2}+\sigma_{\ln f_{\mathrm{m}}}{ }^{2}\right)\right]
\end{gathered}
$$

where $\mu_{\ln X}=\ln \mu_{X}-0.5 \ln \left[1+V_{X}^{2}\right]$ denotes the mean; and $\sigma_{\ln X} \approx V_{X}$ the standard deviation of $\ln X\left(V_{X}=\sigma_{X} / \mu_{X}\right.$ denotes the coefficient of variation of $\left.X\right)$. The strength characteristics of masonry can thus be assessed on the basis of analytical relationships without the use of specialised software products.

Characteristic and design values are usually defined as a fractile of the probability distribution of a material parameter. A fractile of the lognormal distribution $f_{p}$ is obtained as:

$$
f_{p}=\mu_{f} \exp \left\{u_{p} \sqrt{ }\left[\ln \left(1+V_{f}^{2}\right)\right]\right\} / \sqrt{ }\left(1+V_{f}^{2}\right)
$$


where $u_{p}=$ fractile of the standardised normal distribution corresponding to probability $p$. The fractile is obtained as a value of the inverse distribution function of the standardised normal distribution, $u_{p}=\Phi^{-1}(p)$.

While the characteristics of $f_{\mathrm{b}}$ and $f_{\mathrm{m}}$ need to be evaluated for each structure individually, the models for the uncertainties should be based on calibration of test methods. The coefficient $K$ should describe model uncertainties covering the model simplification, lack of experimental data, and effect of unknown workmanship quality. Unlike for $f_{\mathrm{b}}$ and $f_{\mathrm{m}}$, it is usually impossible to obtain experimental data for the coefficient $K$ in the assessment of a specific structure. Its probabilistic model was thus derived on the basis of previous experience and assessment of experimental data [4].

Table 1 gives indicative coefficients of variation of $K$ and $\theta$ for selected test methods widely used for the investigation of historic masonry. All the methods are assumed to be applied by experienced staff to provide unbiased results. The presented values follow from the comparison of strengths obtained by a selected technique with those obtained in a press. The method for statistical determination of resistance models provided in EN 1990:2002 for basis of structural design is applied. Table 1 provides an indication for selection of the test method and also for the decision on a number of tests.

It is emphasised that the coefficients of variation are based on a limited amount of available experimental data, covering an incomplete range of conditions that may appear when investigating historic masonry. Therefore, the values in Table 1 should be considered indicative.

\subsection{Deterioration effects}

It is assumed that the experimental data used to establish the model for the coefficient $K$ do not cover effects $X_{i}$ :

(1) The regularity of the masonry unit bond and filling of joints with mortar $\left(X_{1}\right)$;

(2) Increased moisture $\left(X_{2}\right)$ and

(3) Vertical and inclined cracks in masonry $\left(X_{3}\right)$.

If applicable, all these effects $X_{i}$ likely decrease the mean value and increase variability of the masonry strength. Further, none of these effects is assumed to be explicitly included in masonry strength according to eqn. (1) or (3).

In the absence of statistical data it is proposed to quantify these effects using the information on partial factors given in the text below eqn. (2). The partial factor $\gamma_{\mathrm{m} i}$ for the deterioration effect $X_{i}$ is estimated on the basis of inspection of the historic masonry. Based on experience with probabilistic modelling, an effect $X_{i}$ may be differentiated with respect to its influence on masonry strength as follows:

- Negligible effect is associated with a partial factor $\gamma_{\mathrm{m} i}=1$ corresponding to the coefficient of variation $V_{X i} \approx 0$; 
- For a small effect when $0.85 \leq \gamma_{\mathrm{m} i} \leq 1.1$ the coefficient of variation $V_{X i} \approx 0.05$ is accepted;

- Significant effect for which $\gamma_{\mathrm{m} i}>1.1$ corresponds to $V_{X i} \approx 0.1$.

Table 1: Indicative coefficients of variation $V_{K}$ and $V_{\theta}$ (rounded up to 0.05 ).

\begin{tabular}{|c|c|c|c|c|c|c|}
\hline$X$ & Variable & \multicolumn{4}{|c|}{$V_{X}$} & Source \\
\hline$K$ & $\begin{array}{l}\text { Model variable from } \\
\text { eqn. }(1)^{*}\end{array}$ & \multicolumn{4}{|c|}{0.2} & [4] \\
\hline \multicolumn{7}{|c|}{ Uncertainty in estimation of the mean } \\
\hline$n$ & Sample size $n$ & $n=1$ & $n=5$ & $n=15$ & $n=30$ & \\
\hline \multirow{3}{*}{$\theta_{\mathrm{b}}$} & $\begin{array}{l}\text { Tests in a press on } \\
\text { small specimens }\end{array}$ & 0.05 & 0.05 & 0.05 & 0.05 & [4] \\
\hline & $\begin{array}{l}\text { Modified percussion } \\
\text { drill with indenter } \\
\text { complemented by } \\
\text { revolution counter and } \\
\text { sensor of acting } \\
\text { force }\end{array}$ & 0.7 & 0.45 & 0.2 & 0.15 & $\begin{array}{l}\text { derived } \\
\text { from } \\
\text { data } \\
\text { in }[6,7]\end{array}$ \\
\hline & $\begin{array}{l}\text { Schmidt hammer (type } \\
\mathrm{L} \text {, calibration curve } \\
\text { verified for tests of } \\
\text { bricks by laboratory) }\end{array}$ & 0.9 & 0.6 & 0.25 & 0.2 & $\begin{array}{l}\text { derived } \\
\text { from } \\
\text { data } \\
\text { in }[6,7]\end{array}$ \\
\hline \multirow[t]{2}{*}{$\theta_{\mathrm{m}}$} & $\begin{array}{l}\text { Modified percussion } \\
\text { drill (general } \\
\text { calibration curve) }\end{array}$ & 0.2 & 0.15 & 0.1 & 0.05 & {$[4,6]$} \\
\hline & $\begin{array}{l}\text { Hardness tester } \\
\text { developed at Klokner } \\
\text { Institute (KI) for tests } \\
\text { of mortar strength }\end{array}$ & 0.3 & 0.2 & 0.1 & 0.05 & $\begin{array}{l}\text { long- } \\
\text { term data } \\
\text { of KI }\end{array}$ \\
\hline
\end{tabular}

${ }^{*}$ The ratio of mean to nominal value of $K$ is about 1.25 [4] (without degradation effects). ${ }^{* *} V_{\theta \mathrm{b}}=0.05$ is considered as a minimum value.

${ }^{* * *}$ Using general calibration curve, assuming at least three tests in press are used to calibrate the test method.

${ }^{* * * *}$ Using calibration curve verified by KI, no calibration by destructive tests is assumed.

Further, the semi-probabilistic (Level I) method according to EN 1990:2002 (for details see [8]) leads to a partial factor for lognormally distributed $X_{i}$ with a unit characteristic value:

$$
\gamma_{\mathrm{mi}} \approx 1 /\left[\mu_{X i} \times \exp \left(-u_{p} V_{X i}\right)\right]
$$

where $u_{p}=\alpha_{R} \beta_{\mathrm{t}}=0.32 \times 3.8=1.22$ is the fractile of the standardised normal distribution; $\alpha_{R}=$ FORM sensitivity factor $(0.32$ for a non-dominant resistance 
variable according to ISO 2394:1998); and $\beta_{\mathrm{t}}=$ selected target reliability index (in common cases 3.8 according to $E N$ 1990:2002).

For selected values of $\gamma_{\mathrm{m} i}$, the mean values $\mu_{X i}$ obtained from eqn. (7) are indicated in Table 2 . Note that the effect of change in the target reliability index $\beta_{\mathrm{t}}$ on $\mu_{X i}$ is minor. For instance all $\mu_{X i}$-values reduce by about $0.01-0.02$ when $\beta_{\mathrm{t}}=$ 3.1 is accepted for historic structure instead of $\beta_{\mathrm{t}}=3.8$ as proposed in [4].

Table 2: Indicative statistical characteristics of the deterioration effects influencing masonry strength corresponding to a selected partial factor $\gamma_{\mathrm{m} i}$.

\begin{tabular}{|c|c|c|c|c|}
\hline Importance of effect & $\gamma_{\mathrm{m} i}$ & Distr. & $\mu_{X i}$ & $V_{X i}$ \\
\hline Negligible & 1.0 & deterministic & 1.0 & 0 \\
\hline \multirow{4}{*}{ Small } & 0.85 & \multirow{4}{*}{ lognormal } & 1.25 & \multirow{4}{*}{0.05} \\
\hline & 0.95 & & 1.12 & \\
\hline & 1.05 & & 1.01 & \\
\hline & 1.1 & & 0.97 & \\
\hline \multirow[t]{2}{*}{ Significant } & 1.2 & \multirow[t]{2}{*}{ lognormal } & 0.94 & \multirow[t]{2}{*}{0.1} \\
\hline & 1.4 & & 0.81 & \\
\hline
\end{tabular}

\section{Case study}

\subsection{Fortress in Terezin}

The fortress in Terezin (Czech Republic) was built in the late $18^{\text {th }}$ century. It consists of a citadel and a walled town (Figure 1). The total area of the fortress was about $4 \mathrm{~km}^{2}$ with a capacity of 11000 soldiers. Trenches and low-level areas around the fortress could be flooded for the purpose of defence. This masterpiece of defence heritage is a national monument and is included in the list of Czech sites to be nominated for inclusion in the UNESCO World Heritage List.

Inspections in 2012 revealed severe deterioration of masonry walls surrounding the town. The case study is focused on the most critical area - wall supporting a local road (Figures 1 to 3 ). The upper part of the wall, made of clay bricks, is unfavourably affected by increased moisture $(\sim 17 \%)$ and freeze-thaw cycles. The moisture is primarily caused by malfunctioning of drainage of the road; less significantly by precipitations. The masonry strength is to be estimated in order to verify reliability of the wall and decide on construction interventions.

\subsection{Design value of masonry strength using the partial factor method}

Experimental investigation provided test results of masonry units (using the Schmidt hammer of the type N-34) and mortar (using the hardness tester developed at the Klokner Institute). Strengths of masonry units and mortar were 


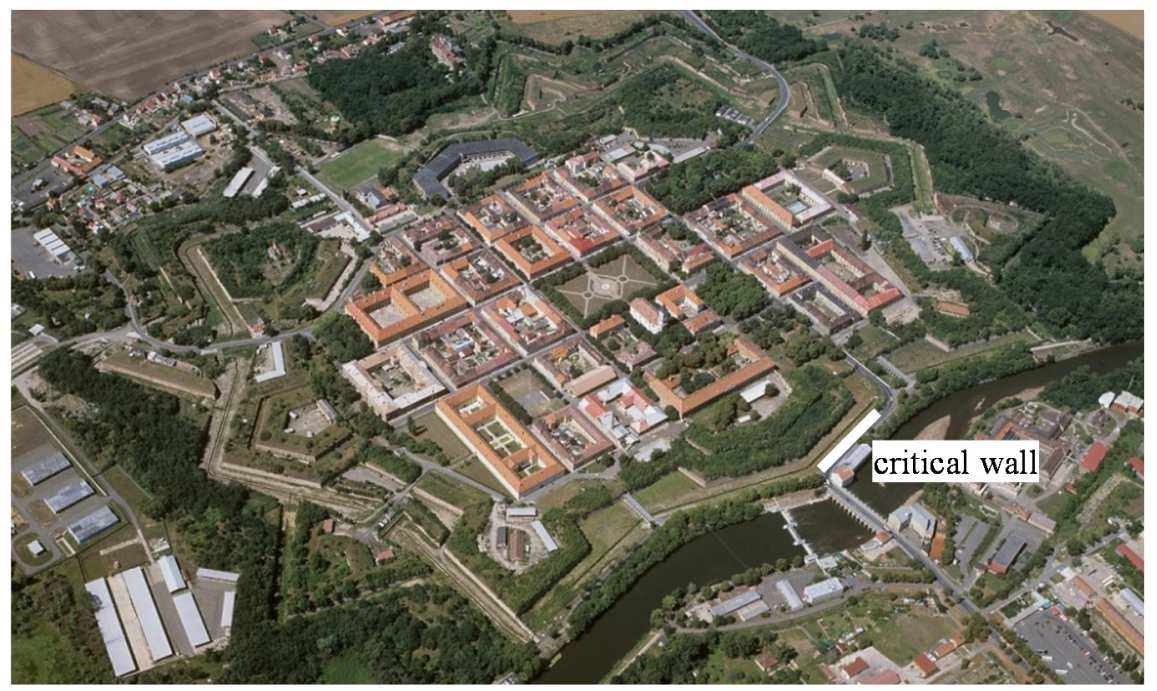

Figure 1: $\quad$ Fortress in Terezin - the walled town and critical wall.

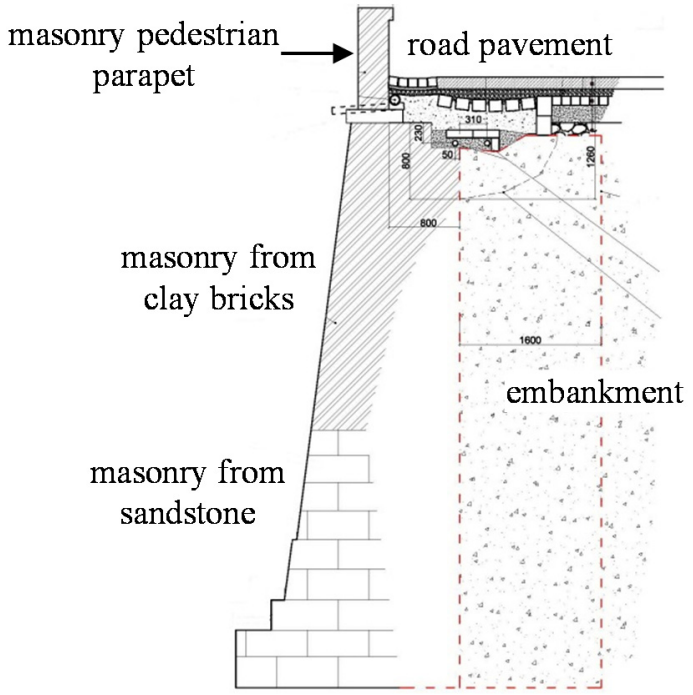

Figure 2: Cross section of the critical wall. 


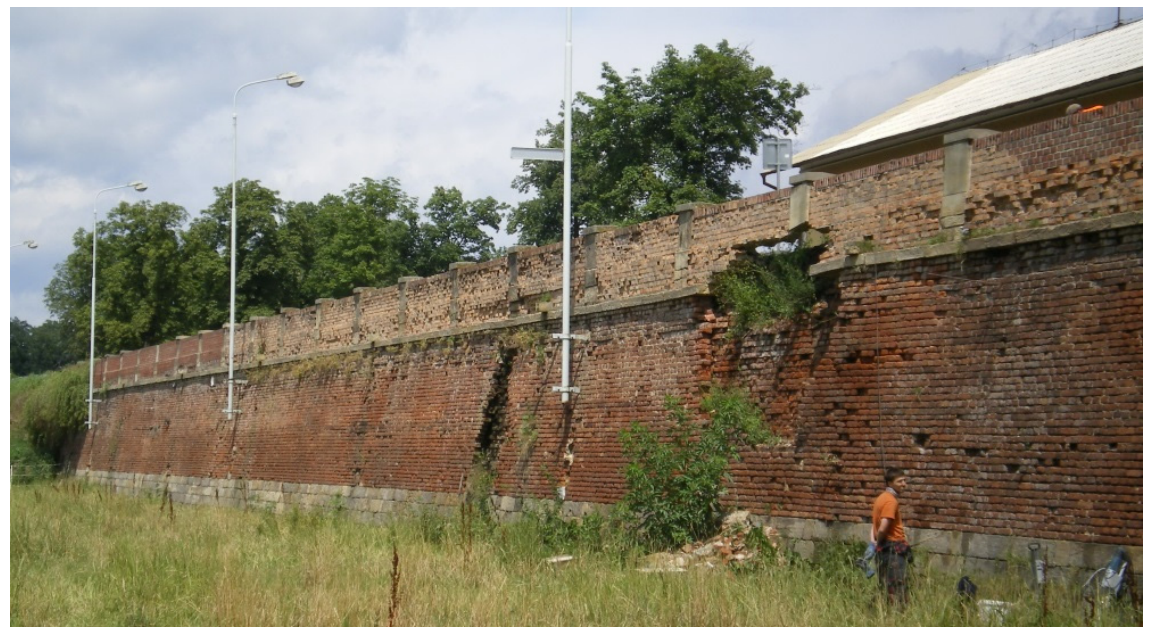

Figure 3: Deterioration of the critical wall.

measured at six locations. No observation is identified as an outlier. The following characteristics are obtained using eqn. (4):

- Strength of masonry units: $\mu_{f \mathrm{~b}}=5.6 \mathrm{MPa} ; \sigma_{f \mathrm{~b}}=0.97 \mathrm{MPa} ; V_{f \mathrm{~b}}=0.17$;

- Strength of mortar: $\mu_{f \mathrm{~m}}=0.46 \mathrm{MPa} ; \sigma_{f \mathrm{~m}}=0.15 \mathrm{MPa} ; V_{f \mathrm{~m}}=0.34$.

The characteristic masonry strength is obtained from eqn. (1); $f_{\mathrm{k}}=$ $0.5 \times 5.6^{0.65} \times 0.46^{0.25}=1.25 \mathrm{MPa}$ (with $K_{\text {nom }}=0.5$ for the group of masonry units $2 \mathrm{a}$, and $\alpha=0.65$ and $\beta=0.25$ according to the Czech National Annex to ISO 13822:2010). The design value of masonry strength $f_{\mathrm{d}}$ is derived from the characteristic value and the partial factor $\gamma_{M}=2.4$ obtained as the product of:

- The basic value $\gamma_{\mathrm{m} 0}=2.0$ for masonry of full masonry units laid on general purpose mortar in accordance with EN 1996-1-1:2005;

- $\gamma_{\mathrm{m} 1}=1.0$ for irregular bond and perfect filling of joints with mortar;

- $\gamma_{\mathrm{m} 2}=1.2$ taking into account the effect of averaged moisture $17 \%$;

- $\gamma_{\mathrm{m} 3}=1.0-$ no significant cracks observed.

Therefore, $f_{\mathrm{d}}=1.25 / 2.4=0.52 \mathrm{MPa}$ is obtained.

\subsection{Design value of masonry strength using the probabilistic model}

The effect of moisture, described by $\gamma_{\mathrm{m} 2}=1.2$, can be expressed in the probabilistic analysis by a lognormal variable with $\mu_{X 2}=0.94$ and $V_{X 2}=0.1$ (Table 2). The updated coefficient $K^{\prime}=X_{2} K$ covers the effect of increased moisture; its statistical characteristics are: 


$$
\begin{gathered}
\mu_{K},=\mu_{X 2} \times\left(\mu_{K} / K_{\text {nom }}\right) \times K_{\text {nom }}=0.94 \times 1.25 \times 0.5=0.59 ; \\
V_{K}=\sqrt{ }\left(0.1^{2}+0.2^{2}\right)=0.22
\end{gathered}
$$

Product of two lognormal variables is also lognormal.

For full clay bricks and a general purpose mortar $\alpha=0.73$ and $\beta=0.16$ are suggested in JCSS PMC [5] and adopted here. Considering $V_{\theta \mathrm{b}}=0.57$ and $V_{\theta \mathrm{m}}=$ 0.19 for $n=6$ (Table 1), the simplified probabilistic model (eqn. (3) to (5)) yields $\mu_{f}=1.76 \mathrm{MPa} ; V_{f}=0.47 ; f_{\mathrm{d}}=0.52 \mathrm{MPa}$. The design value is here assessed as the fractile of masonry strength corresponding to probability of $6.6 \%$ derived for $\beta_{\mathrm{t}}=$ 3.1 [4]. In this case the probabilistic design value is equal to the value obtained deterministically.

Normally, the probabilistic approach leads to greater strengths than the partial factor method that is intentionally conservative to cover a wide range of materials and test methods $[4,6,7,9,10]$. The observed discrepancy is attributed primarily to the effect of statistical uncertainty (lack of data). In the probabilistic model this effect is considered by the uncertainties $\theta_{\mathrm{b}}$ and $\theta_{\mathrm{m}}$ while no adequate consideration is (for simplification) accepted in the deterministic approach. Note that the deterministic model regarding the statistical uncertainty was proposed in [4].

To improve the estimate of $f_{\mathrm{d}}$, it was decided to verify strengths of masonry units and mortar at other nine locations in the second step of the assessment. In total 15 measurements are now available for $f_{\mathrm{b}}$ and $f_{\mathrm{m}}$. For purposes of illustration it is assumed that mean values and standard deviations are the same as in the first step (with six measurements).

The design value obtained by the partial factor method is still $f_{\mathrm{d}}=0.52 \mathrm{MPa}$. The coefficients of variation $V_{\theta \mathrm{b}}$ and $V_{\theta \mathrm{m}}$ are the only input parameters of the probabilistic model that need to be updated. Considering $V_{\theta \mathrm{b}}=0.25$ and $V_{\theta \mathrm{m}}=0.1$ for $n=15$ (Table 1), the simplified probabilistic model yields $\mu_{f}=1.80 \mathrm{MPa} ; V_{f}=$ 0.30 and $f_{\mathrm{d}}=0.84 \mathrm{MPa}$. The design value thus increases by about $60 \%$.

\subsection{Proposed interventions and present state}

It was recommended to repair the drainage of the road to decrease moisture and avoid further deterioration of the masonry. Based on reliability assessment of the critical wall exposed to earth pressure (considering traffic actions on the road), the following temporary traffic restrictions were advised:

- Shift a traffic lane $2 \mathrm{~m}$ from the pedestrian parapet (see Figure 2);

- Restrict access of vehicles over $6 \mathrm{t}$ in the traffic lane adjacent to the pedestrian parapet.

In addition to the rehabilitation of the drainage, maintenance of the masonry is needed to preserve authentic appearance of the walls and the cultural heritage value of the site. The maintenance is delayed as the intention to imitate original masonry units is hindered by shortage of the clay similar to that used for original bricks. Further, non-standard dimensions of bricks and application of production process similar to the original one substantially increase costs of the maintenance. 


\section{Conclusions}

Historic defensive structures are made of various types of masonry and the information on mechanical properties of masonry components has to be obtained by testing. Estimation of masonry strength using measurements affected by various types of uncertainties appears to be a key issue of the reliability assessment. When compared to deterministic methods the probabilistic assessment provides better description of randomness of basic variables, statistical uncertainties and uncertainties in test methods and theoretical models. The proposed probabilistic model for masonry strength is suitable for practical applications as it does not require any specialised software. The design value of masonry strength obtained probabilistically may be considerably greater than the value obtained deterministically. Statistical uncertainty due to lack of data may significantly affect the predicted design value.

\section{Acknowledgements}

This study has been conducted at the Czech Technical University in Prague within the research project NAKI DF12P01OVV040 Assessment of Safety and Working Life of Industrial Heritage Buildings supported by the Ministry of Culture of the Czech Republic.

\section{References}

[1] Mojsilovic, N. \& Faber, M.H., Probabilistic assessment of masonry compressive strength. Proc. ICOSSAR 2009, eds. H. Furuta, D.M. Frangopol \& M. Shinozuka, CRC Press/Balkema: Leiden, pp. 3609-3613, 2009.

[2] Stewart, M.G. \& Lawrence, S.J., Model Error, Structural Reliability and Partial Safety Factors for Structural Masonry in Compression. Masonry International, 20(3), pp. 107-116, 2007.

[3] Stewart, M.G. \& Lawrence, S.J., Structural Reliability of Masonry Walls in Flexure. Masonry International, 15(2), pp. 48-52, 2002.

[4] Sykora, M., Cejka, T., Holicky, M. \& Witzany, J., Probabilistic Model for Compressive Strength of Historic Masonry. Proc. ESREL 2013, eds. R.D.J.M. Steenbergen, P. Van Gelder, S. Miraglia \& A.C.W.M. Vrouwenvelder, CRC Press/Balkema: Leiden, pp. 2645-2652, 2013.

[5] JCSS, JCSS Probabilistic Model Code, Joint Committee on Structural Safety: 2001.

[6] Cejka, T., Holicky, M., Sykora, M. \& Witzany, J., Strength assessment of historic brick masonry (accepted for publication). Journal of Civil Engineering and Management, 2014.

[7] Cejka, T., Holicky, M., Sykora, M. \& Witzany, J., Assessment of Compressive Strength of Historic Mixed Masonry (accepted for publication). Journal of Civil Engineering and Management, 2014. 
[8] Caspeele, R., Sykora, M., Allaix, D.L. \& Steenbergen, R., The Design Value Method and Adjusted Partial Factor Approach for Existing Structures. Structural Engineering International, 23(4), pp. 386-393, 2013.

[9] Sykora, M. \& Holicky, M., Evaluation of Compressive Strength of Historic Masonry Using Measurements. Advanced Materials Research, 923(-), pp. 213-216, 2014.

[10] Sykora, M. \& Holicky, M., Compressive Strength of Deteriorated Historic Masonry Based on Measurements (submitted for publication). Proc. ICNAAM 2014, American Institute of Physics Inc.: College Park (USA), pp. 4, 2014. 